\title{
STUDIES ON THE PERCENTAGE VARIATION OF RESISTANCE OF POLYMER THICK FILM (PTF) RESISTORS
}

\author{
SHEN-LI FU, MONG-SONG LIANG, TOYOTARO SHIRAMATSU and TIEN-SHOU WU \\ Department of Electrical Engineering, National Cheng Kung University, Tainan, Taiwan, Republic of \\ China
}

\begin{abstract}
The percentage variation of resistance of polymer thick film (PTF) resistors has been studied. Two different kinds of polymer resin, i.e., epoxy resin and polyimide resin, as well as four different kinds of carbon black are adopted in the preparations of PTF resistors. Among the four different kinds of carbon black, i.e., $\varepsilon 45$, MA-100, MA-600 and HS-500 (all trade names), HS-500 shows the least variation with temperature changes. This can be attributed to the high structure property of HS-500 carbon black. The variation will be lowered down with an increase in the loading fraction of carbon black in PTF resistors. Same tendency will be observed in both epoxy and polyimide resin PTF resistors. However, the variations are smaller in polyimide resin resistors than in epoxy resin resistors. The percentage variations of resistance of PTF resistors, after stored at $120^{\circ} \mathrm{C}$ for $1000 \mathrm{hrs}$, or after 25 cycle thermal shock tests, or dipped in a $200^{\circ} \mathrm{C}$ solder pot for three seconds, as well as the variations after the short term overload tests, have also been measured and studied. The variations are still smaller in polyimide resin PTF resistors. A possible explanation on this smaller variation in polyimide resin PTF resistor is also presented.
\end{abstract}

\section{INTRODUCTION}

From the previous studies of the authors, ${ }^{1,2}$ it is known that the mixtures of carbon black and polymer resins can be utilized as thick film resistor. Their electrical properties: such as sheet resistivity, ${ }^{3,4} \mathrm{TCR},{ }^{5}$ and current noise,${ }^{6}$ have been obtained and studied. However, TCRs are only the measures of resistance changes between two specific temperatures, i.e., $25^{\circ} \mathrm{C}$ for Hot TC and a $5^{\circ} \mathrm{C}$ to $-55^{\circ} \mathrm{C}$ for Cold TCR. No information of resistance variations, for the temperatures in between, can be known. So the percentage variations of resistance of PTF resistors prepared by different ingredients are measured and studied to try to get a better understanding about the thermal effects on PTF resistors.

In order to find out the effects of different kinds of carbon black, as well as different kinds of polymer resins, on the stability of resistance values of PTF resistors, several experiments have been conducted. Besides the measurements of resistance variations with respect to temperature changes, the percentage variation of resistance after being stored at $120^{\circ} \mathrm{C}$ for $100 \mathrm{hrs}$, or after thermal shock tests, or the resistance variations after short term overload (STOL) tests or Solder dipping tests, are also measured and studied. A possible explanation on the experimental results will also be given.

\section{EXPERIMENTAL PROCEDURE}

The experimental procedures will, in general, be the same as those in the previous studies. There are two kinds of polymer resin used, i.e., epoxy resin and polyimide resin. Four different kinds of carbon black, i.e., \#45, MA-100, MA-600 and HS-500, are adopted in the preparations of PTF resistors. Their physical properties have also been stated in the previous studies.

The conductor terminations are prepared by the mixtures of $\mathrm{Ag} / \mathrm{Cu}$ powder with polymer resins. The resin used in the preparation of conductor termination will be the same with the resin used in the overlapped resistor.

The PTF resistor pastes are prepared by mixing of carbon blacks with polymer resins, and xylene or cyclohexaneon is adopted as the diluent. The substrates used are polyimide glass fibre laminates. After screenprinting on the substrate, the PTF resistors are dried and then cured. The curing conditions are at $200^{\circ} \mathrm{C} / 10$ hrs for epoxy resin PTF resistors and $250^{\circ} \mathrm{C} / 10 \mathrm{hrs}$ for polyimide resin PTF resistors.

The percentage variations of resistance are measured on the cured PTF resistors in a thermostat chamber. The variations are measured for every $25^{\circ} \mathrm{C}$ temperature change. Starting from room temperature, however, the lowest temperature is down to $-55^{\circ} \mathrm{C}$ and the 
highest is $125^{\circ} \mathrm{C}$. There are 15 pieces of each sample point.

Long term resistance drifts are measured and expressed as percentage variations of resistance. The drift tests are carried out in the thermostat chamber by setting the temperature at $120^{\circ} \mathrm{C}$. The resistance values are measured after $1000 \mathrm{hrs}$.

The effect of solder dipping on the resistance variation is measured at room temperature. By dipping the resistor samples into a $200^{\circ} \mathrm{C}$ solar pot for three seconds, then take it out and measure the resistance values till its cooled down. The results are also expressed as percentage variations.

Thermal shock tests are practiced by placing the samples at $100^{\circ} \mathrm{C}$ and $0^{\circ} \mathrm{C}$ for 30 seconds each time, and the process is repeated 25 times. The resistance variations are measured.

The short term overload (STOL) test is carried out by applying voltage to the resistor samples, which are square in shape and the length of each side is $2 \mathrm{~mm}$, till the power reaches a value of $250 \mathrm{~mW}$. After $20 \mathrm{sec}-$ onds, remove the voltage source and record the resistance variation after it has been in room temperature for 30 minutes. The rating of the resistors are approximately $100 \mathrm{~mW} / 4 \mathrm{~mm}^{2}$.

\section{EXPERIMENTAL RESULTS}

Figure 1 and Figure 2 are the relationships between $\Delta \mathrm{R} / \mathrm{R} \times 100 \%$ and the temperature of carbon black/ polyimide resin PTF resistors. In Figure 1 the contnet of carbon black is $10 \%$ (wt.), and in Figure 2 it is $20 \%$ Four different kinds of carbon black are used. In both Figure 1 and Figure 2, the HS-500 carbon black shows the smallest variation. The reason might be attributed to the high structure ${ }^{7}$ property of HS-500 carbon black. It is smallest both from $25^{\circ} \mathrm{C}$ to $125^{\circ} \mathrm{C}$ to $-55^{\circ} \mathrm{C}$.

No unique relationship can be obtained between carbon blacks and the percentage variations. However, if we neglect the results of \#45 carbon black temporarily, then a resistor with higher sheet resistivity (MA-100 in this case) will show a higher variation, both from $25^{\circ} \mathrm{C}$ to $125^{\circ} \mathrm{C}$ and from $25^{\circ} \mathrm{C}$ to $-55^{\circ} \mathrm{C}$. The result is coincident with the works done by other authors, ${ }^{7,8}$ and all variations are in negative direction when temperature goes higher. A decrease in the percentage variation of resistance has also been observed when the content of carbon black is increased.

In Figure 3(a) and Figure 3(b), there shows the resistance variations in epoxy resin and in polyimide resin PTF resistors. Here the temperature range is from $25^{\circ} \mathrm{C}$ to $125^{\circ} \mathrm{C}$ and the content of carbon black is $20 \%$ in weight. In both resistors, HS-500 carbon black still possess the smallest variation. The percentage variations observed in Figure 3(a), show a direct relationshi] with the oil absorption property can be taken as a measure of the structure of carbon black, ${ }^{9}$ lower structure carbon black, which is higher in sheet resistivity value, will show higher variation. This result is coincident with that discussed on above.

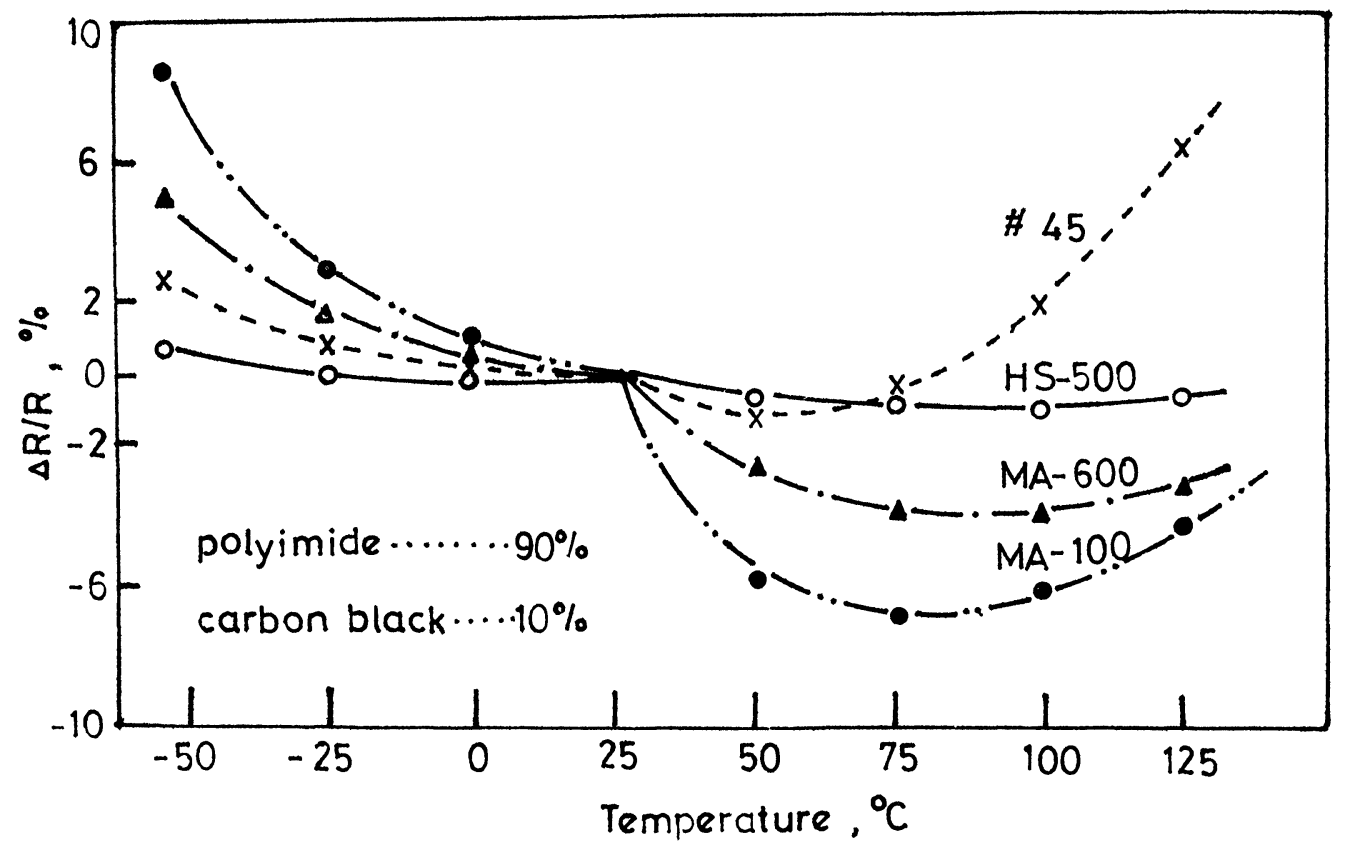

FIGURE $1 \Delta R / R$ versus temperature of carbon black/polyimide resin resistors (I). 


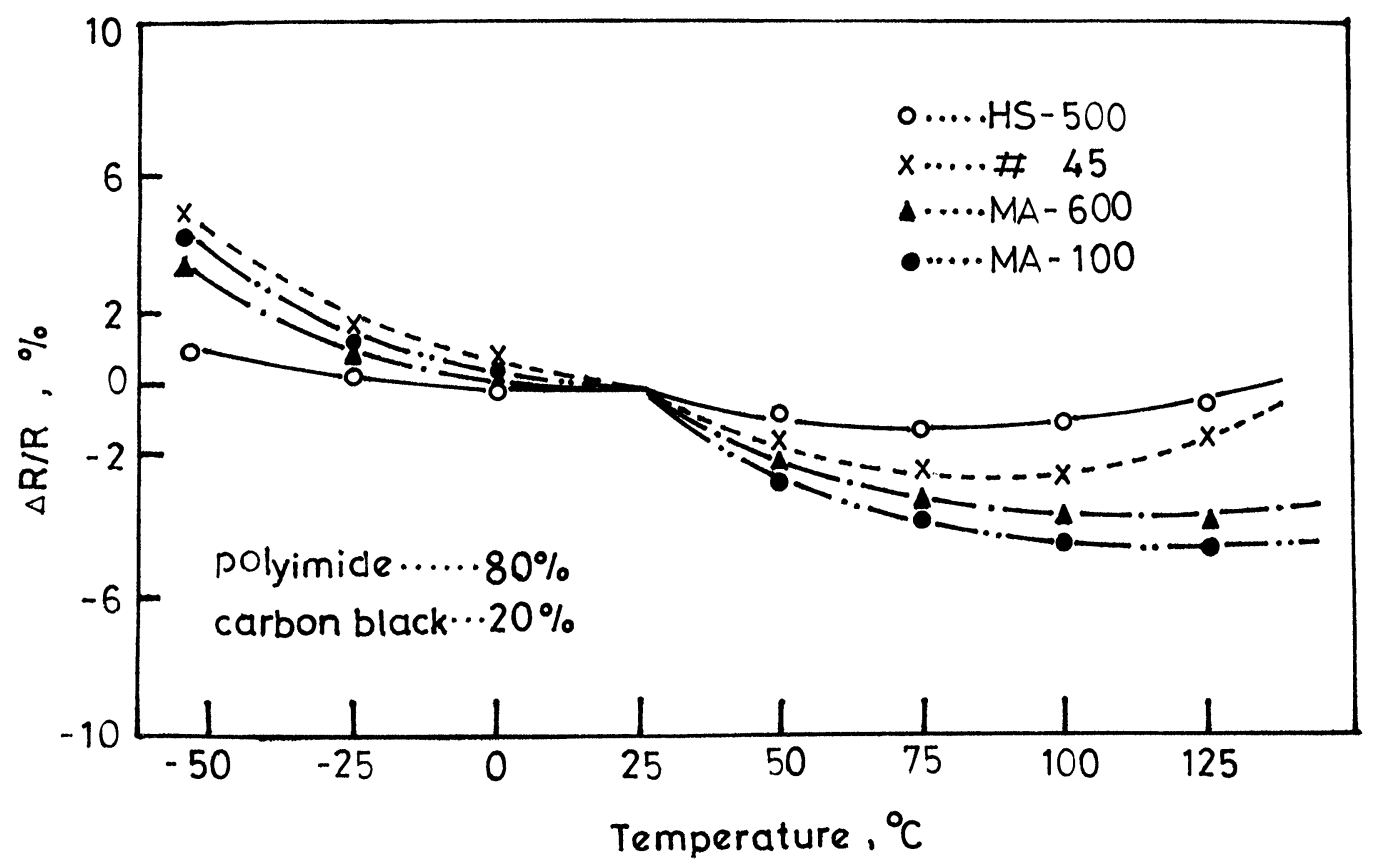

FIGURE $2 \Delta R / R$ versus temperature of carbon black/polyimide resin resistors (II).
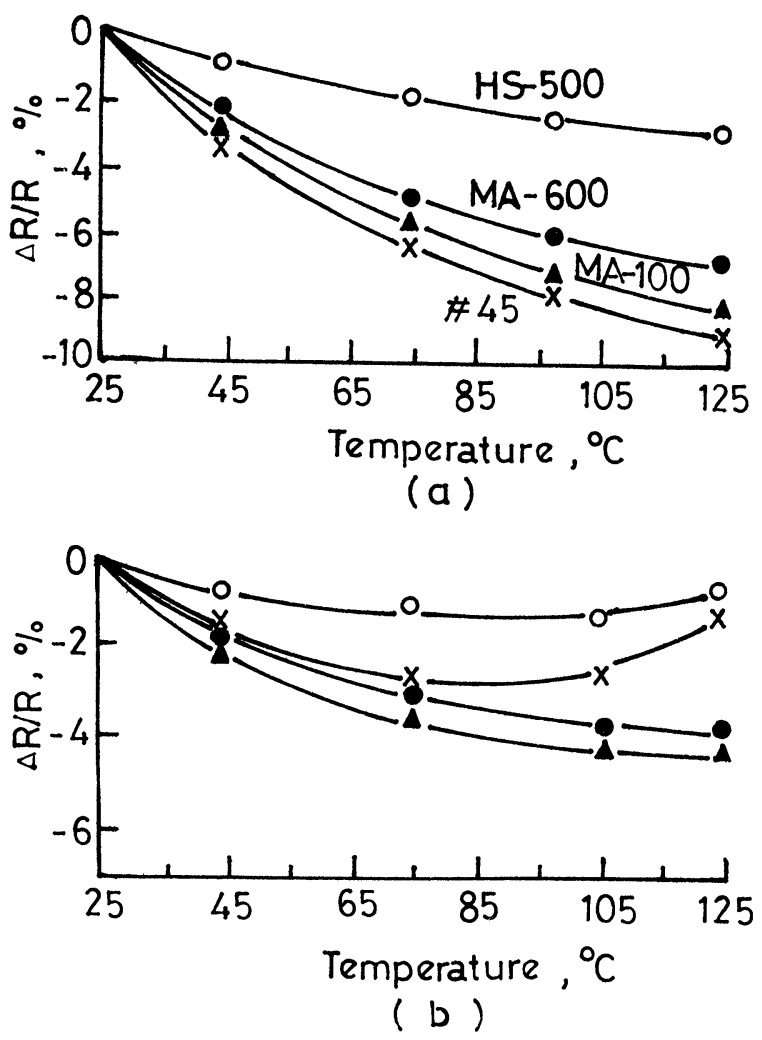

FIGURE $3 \quad \Delta R / R$ versus temperature of (a) carbon black/ epoxy resin, (b) carbon black/polyimide resin PTF resistors.
The \#45 carbon black in Figure 3(b), like it is in both Figure 1 and Figure 2, is still the only exception and will be discussed later. However, almost all other variations are negative in values, and are larger in epoxy resin PTF resistors than in polyimide resin PTF resistors.

Figure 4 shows the long term resistance drift characteristics. After storing at $120^{\circ} \mathrm{C}$ for $1000 \mathrm{hrs}$, the drift of polyimide resin PTF resistor is within $+2 \%$, while for expoxy resin PTF resistor is within $-6 \%$. The variation of resistance is still larger in epoxy resin resistor than in polyimide resin resistor.

The PTF resistors, after dipped into a $200^{\circ} \mathrm{C}$ solder pot for three seconds, the variations in sheet resistivity is within $1.5 \%$ for both types of PTF resistors. The samples shown in Figure 5 are of different loading fractions of carbon black. The variations are still larger in epoxy resin PTF resistors.

Figure 6 shows the measured variations of PTF resistors after thermal shock tests, i.e., placed at $100^{\circ} \mathrm{C}$ and $0^{\circ} \mathrm{C}$ for 30 seconds each time, and measured after 25 times test. The percentage variations are smaller than $1.5 \%$. The STOL tests carried out on the $2 \mathrm{~mm} \times 2$ $\mathrm{mm}$ resistors (rating $100 \mathrm{~mW}$ ), by applying $250 \mathrm{~mW}$ on it for 20 seconds. The variations measured after 30 minutes power off are shown as Figure 7. The variations are within $1 \%$ and it's still larger in epoxy resin PTF resistors. 


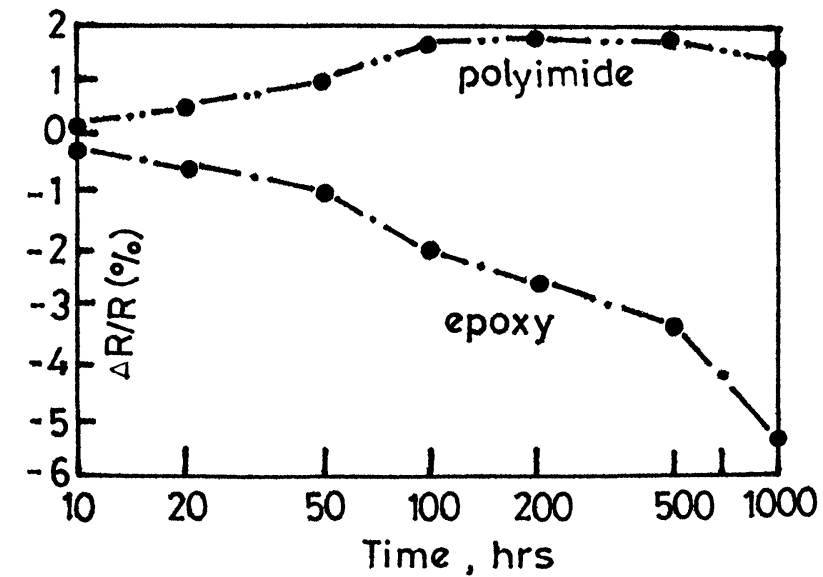

FIGURE 4 Long term drift characteristics of PTF resistors at $120^{\circ} \mathrm{C}$.

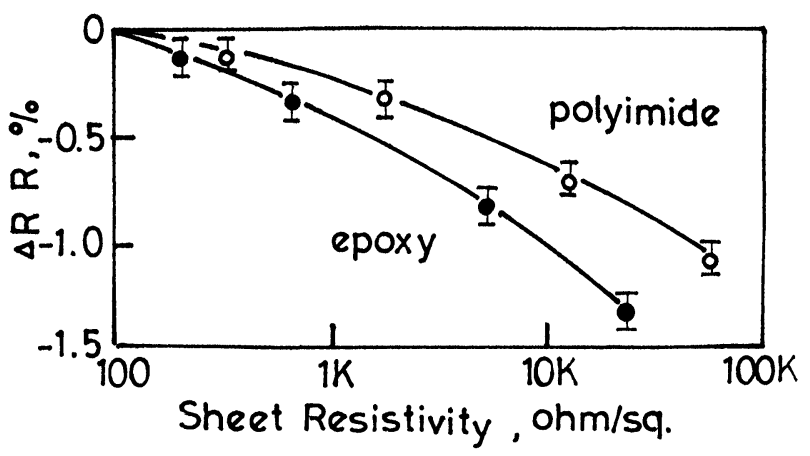

FIGURE $5 \Delta R / R$ after solder dipping $\left(200^{\circ} \mathrm{C} / 3 \mathrm{sec}\right)$.

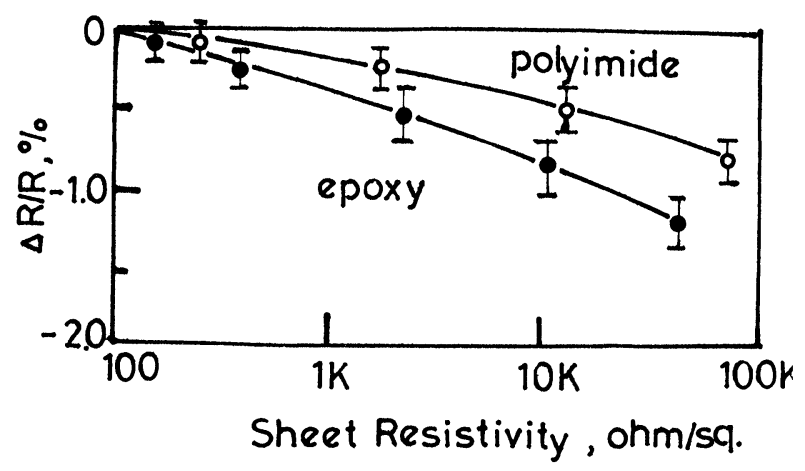

FIGURE $6 \Delta R / R$ after thermal shock tests; (25 cycles: $\left.100^{\circ} \mathrm{C} / 30 \mathrm{sec}+0^{\circ} \mathrm{C} / 30 \mathrm{sec}\right)$

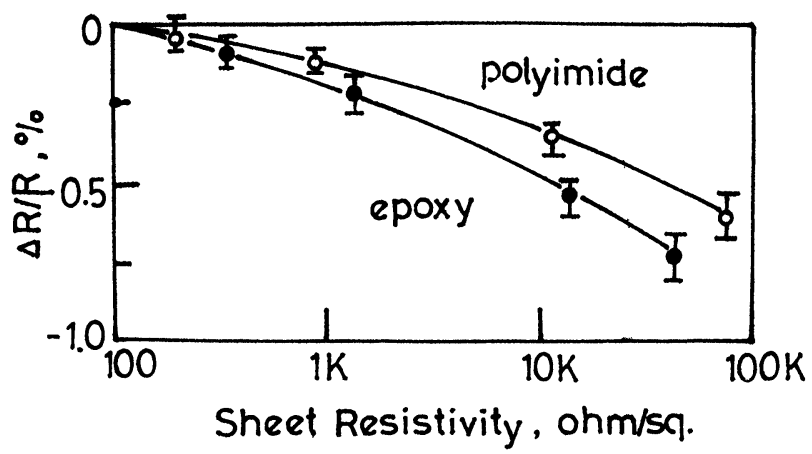

FIGURE $7 \quad \Delta \mathrm{R} / \mathrm{R}$ after short term overload tests; rating: $100 \mathrm{~mW} / 4 \mathrm{~mm}^{2}$, apply: $250 \mathrm{~mW} / 4 \mathrm{~mm}^{2}$ for 20 seconds.

\section{DISCUSSION}

From the experimental results obtained in the study of percentage variations of PTF resistors with temperature changes, it can be seen that \#45 low structure carbon black has shown many distinguishable effects.

In Figure 1, when the temperature is increased from $25^{\circ} \mathrm{C}$, \#45 resistor first showed a negative variation, then it crossed the zero-variation line and toward positive. This might be a result of competition between the Brownian motion of carbon black ${ }^{10}$ and the thermal expansion effect of matrix resin. ${ }^{11}$ At first, when temperature is increased from $25^{\circ} \mathrm{C}$, the Brownian motion of \#45 carbon black is dominant, so a negative variation is observed. However, by further increasing the ambient temperature, the effect of the thermal expansion of polyimide resin will exceed that of the Brownian motion, and a positive variation is expected. The effect of thermal expansion of matrix resin will be decreased with an increase in the amount of carbon black, like that shown in Figure 2. However, the only effect in PTF resistor, from $-55^{\circ} \mathrm{C}$ to $25^{\circ} \mathrm{C}$, seems to be the thermal motion of carbon blacks.

The percentage variations of resistance of PTF resistors, except those prepared by \#45 carbon black, are negative in value. This can be taken as other evidence that the thermal motion of carbon black might be the dominant factor in the resistance variations of PTF resistors, when subjected to temperature changes.

The resistance variations of PTF resistors, after undergoing different tests, are expressed as percentage variations as shown above. The variations are larger than those of the commercial cermet resistors. However, one can see that the PTF resistors prepared by polyimide resin will have smaller variation than those prepared by epoxy resin. The reason that the variation is larger in epoxy PTF resistor than in polyimide resin 
PTF resistor can be understood by considering the strength of linkage in the polymer resins. In polyimide resin PTF resistors, the $\pi$ electrons ${ }^{12}$ will resonate in the polymer and release the resonate in the polymer and release the resonant energy, so the linkage in polyimide resin will be more stable. While in epoxy resin, no such resonance occurs, so the linkage in epoxy resin, no such resonance occurs, so the linkage in epoxy resin is not so stable as in polyimide resin. This might be the reason why the percentage variation of resistance is larger in epoxy resin PTF resistor than in polyimide resin PTF resistor.

\section{CONCLUSION}

Among different kinds of carbon black used in the pref arations of PTF resistors in this study, HS-500 carbon black shows the smallest variation. This can be attributed to the high structure property of HS-500 carbon black.

Almost all variations (except those of \#45 carbon black) show negative values, implying that the Brownia motion of carbon black are more effective than that of the thermal expansion of the matrix resins.

The percentage variations of resistance after long term drift, solder dipping, thermal shock and short term overload tests are, in general, larger than those of cermet type thick film resistors, and implies that the stabil ity of PTF resistors is worse than that of cermet resistors.
The reason that larger variations in resistance are observed in epoxy resin PTF resistors than in polyimide resin PTF resistors can be attributed to the resonance of $\pi$ electrons in polyimide resin. They will release the resonant energy and make the linkage in polyimide resin more stable. While in epoxy resin, no such resonance occurs, so the variations in resistance is larger in epoxy resin PTF resistor under different test conditions.

\section{REFERENCES}

1. S. L. Fu, T. Shiramatsu and T. S. Wu, Proc. 1st IEEE ROC Symp. on Electron Devices \& Materials, 186 (1976).

2. S. L. Fu, T. Shiramatsu and T. S. Wu, Proc. 1st IEEE ROC Symp. on Electron Devices \& Materials, 199 (1976).

3. S. L. Fu, T. Shiramatsu and T. S. Wu, Proc. 29th Electronic Components Conference, 286 (1979).

4. S. L. Fu, to be presented at 30th Electronic Components Conference in San Francisco (April 28-30, 1980).

5. T. S. Wu, T. Shiramatsu, S. L. Fu and M. S. Liang, Proc. Intern. Thin- and Thick Film Tech. Conference, in Ausberg, 34 (1977).

6. S. L. Fu, T. Shiramatsu and T. S. Wu, Proc. European Hybrid Microelectronic Conference, in Ghent, 133 (1979).

7. H. Sugano, Densi Tembo (Jap.), 6, 19 (1969).

8. Hashimodo, Electronic Materials (Jap.) 73 (Feb. 1967).

9. G. Kraus, C. W. Childers and K. W. Rollmann, J. Appl. Polymer Sci., 10, 229 (1966).

10. D. Bulgin, Rubber Chem. and Tech., 19, 667 (1946).

11. Nakashima, Proc. JIEE Symp. on Resistord, 140 (1970).

12. J. P. Suchet, Chemical Physics of Semiconductors, 165 (1969). 

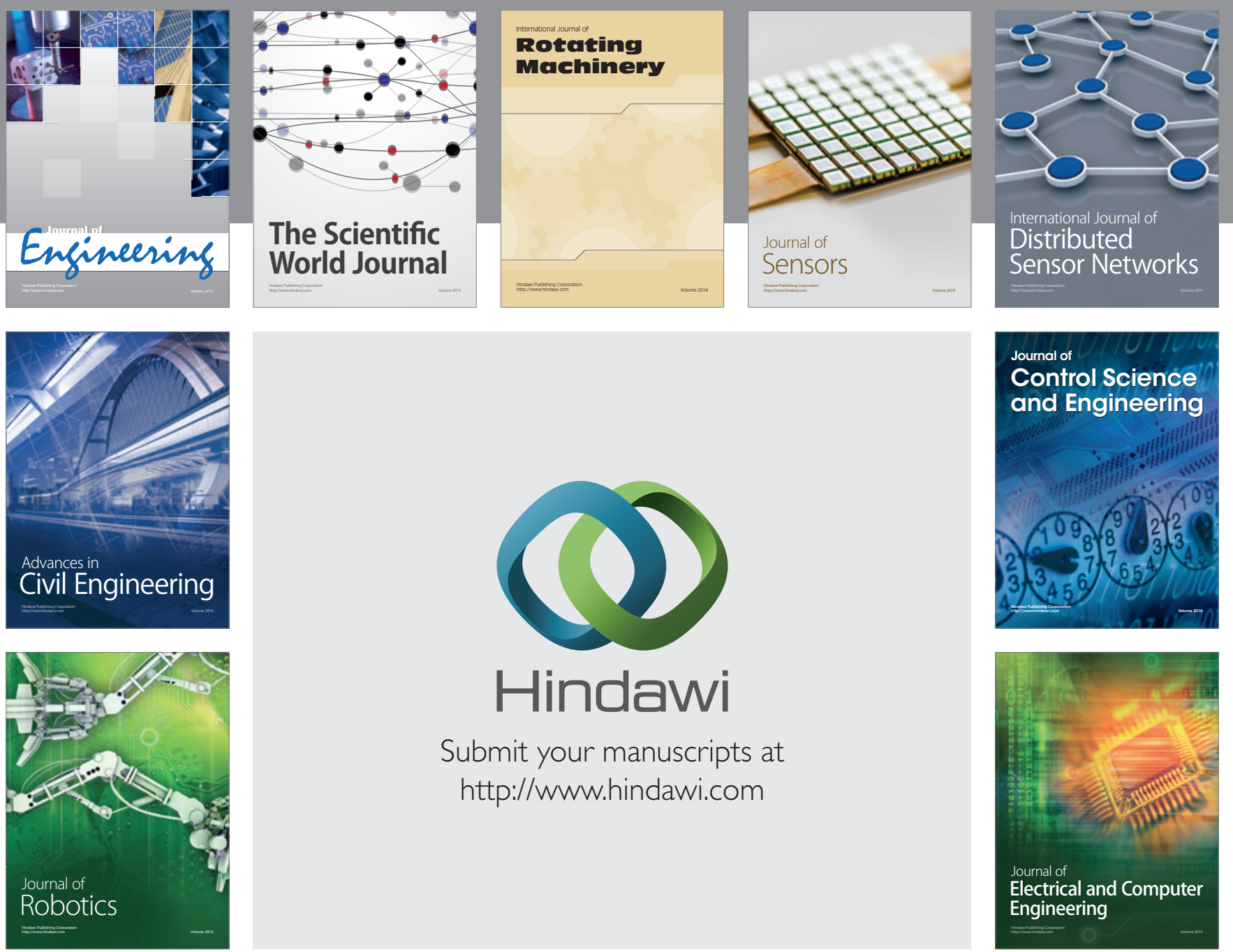

Submit your manuscripts at

http://www.hindawi.com
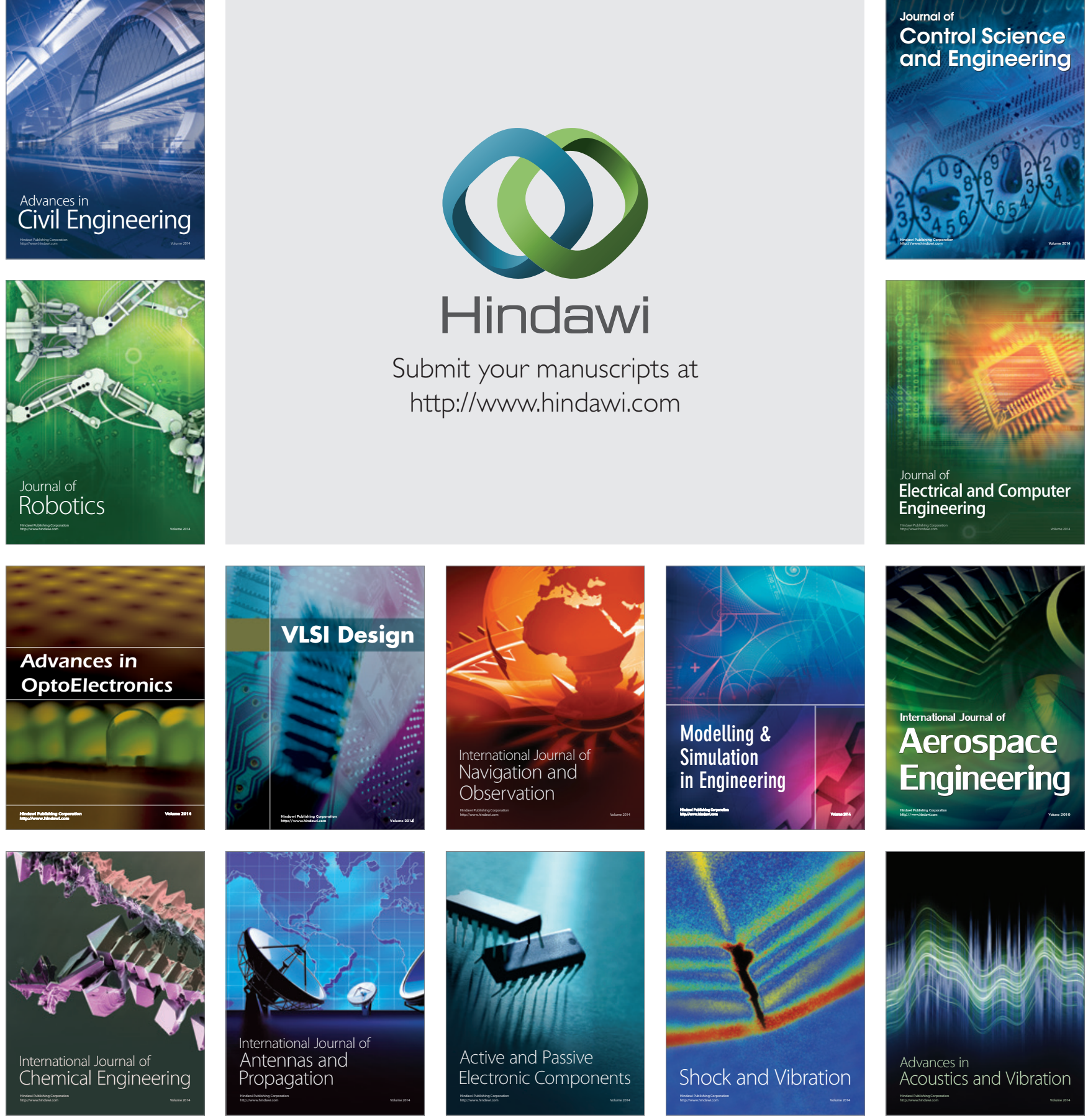